\title{
The Psychic Life and Creativity of the Forms of Life. Some Remarks on Wittgenstein's Philosophy of Psychology*
}

\author{
Emiliano LA LiCATA
}

Recibido: 5 de junio de 2013

Aceptado: 23 de octubre de 2013

\begin{abstract}
Wittgenstein's later philosophy addresses the subject of connection between the psychic life of the individual and social context, represented by language games which are played within a form of life. Sensations and passions are part of the psychic life of the individual; far from being hidden psychological objects of a private Cartesian, they are inseparable from their social redefinition. In fact, they become visible in the context of the game. Wittgenstein argues that there is a transformation of subjective psychic life by learning language games. The psychic life of the individual is then re-organized by learning a socially defined, characteristic behaviour pattern. However, the learning process of the games is complex and non-deterministic, in that it oscillates between degrees of acceptance and degrees of negation of language game rules. Through this oscillation between acceptance and denial of the game rules, it is possible to develop processes which lead to unpredictable changes in the game and in forms of life.
\end{abstract}

Keywords: Psychic life, forms of life, philosophy pf psychology, Wittgenstein.

\section{Some clarifications on Wittgenstenian form of life}

In the article I refer constantly to the Wittgenstenian concept of form of life. In this first paragraph I wish to clarify the way in which I interpret this controversial concept.

\footnotetext{
* The article has been developed within a research project granted by the Research Council of Norway under YGGDRASIL mobility programme 2012-2013.
} 
Right at the beginning of $P I$, in paragraph 19 , Wittgenstein invites us to imagine a simplified language -or at least different from the one we are used to every day. A language "consisting only of orders and reports in battle.-Or a language consisting only of questions and expressions for answering yes and no. And innumerable others." And then he concludes with one of his sibylline phrases: "-And to imagine a language means to imagine a form of life"1. Reading these and similar similar phrases, one often asks oneself: how are concepts of language and form of life bound in the PI? What does "language is a form of life" mean? What does the possibility to imagine innumerable other languages and forms of life mean?

As we know, in PI Wittgenstein gives much consideration to praxis and action: speaking a language means striving to do things with others. Language directly involves the life of players in language games. It is easy to recognize a sort of supremacy of the deed in a notional life. Referring to objects, understanding a phrase, following a rule, meaning and even thinking are activities which involve the players in a regulated flexible space. Those activities involve the ordinary life of language game players. However, when Wittgenstein talks about life, to which life does he refer? To biological life? To social life? And in that case, which kind of biological life? Which kind of social life?

According to me, the concept of life form in PI refers to the life of communities producing cultures and manipulating the natural environment via their culture 2 . These communities are organized through the development of a culture which enters in relation with nature. Cultures developed by communities, via a relationship with the natural environment, permit adaptation to the world: they give meaning to it. Therefore so, form of life is seen as an ongoing process and not something fixed in a static form.

A similar conception of form of life in later Wittgenstein philosophy is theorized by G.H. von Wright in his famous article "Wittgenstein in Relation to His Times"3. He writes:

It was his philosophical conviction that the life of the human individual and therefore also the all individual manifestations of culture are deeply entrenched in basic structures of a social nature. The structures in question are what Wittgenstein called 'Lebensformen', forms of life, and their embodiment in what he called 'Sprachspiele', language-games. They are 'what has to be accepted, the given', the unquestioned basis of all judging and thinking (Cf. Philosophical Investigations, Part II, p. 226; On Certainty, § 229). This basis, to be sure, is not eternal and immutable. It is a product of human history and changes with history. It is something man made, and he changes. But how this happens is, according to Wittgenstein, not to be accounted for by a theory, or

\footnotetext{
1 PI $\$ 19$.

2 See for instance Hacker (2010) and (2011).

3 Von Wright (1982).
} 
foreseen. 'Wer kennt die Gesetze, nach denen die Gesellschaft sich ändert?' ('Who knows the laws according to which society develops?' (Culture and Value, p. 60), he asks, and adds: 'Ich bin überzeugt, da $\beta$ auch der Gescheiteste keine Ahnung hat' ('I am quite sure they are closed book even to cleverest of men' (ibid.)) $)^{4}$.

In these few lines, Von Wright focuses on many concepts regarding Lebensformen and the dynamics which are visible in language games. First, he uses the plural of Lebensform; this means that in Von Wright's view human forms of life are multiple and open to differentiation. He does not discuss just one human form of life, but forms of life which build up ways of living by playing Sprachspiele. Not only does he highlight the intrinsically social nature of the form of life, he adds that this social nature is also political, in the Aristotelian sense: subjects' actions that collectively play language games alter forms of life towards an unpredictable horizon a priori. In other words, the actions of men brought together in communities are, on the one hand, guided by shared habits without rational justification: they are simply accepted 5 . On the other, the actions of socially connected subjects alter and move the background of shared customs belonging to the forms of life in a way which cannot be predicted by a theory. Forms of life are inserted in the flow of history and the dynamics of this history are neither deterministic nor teleological, but simply political, in the sense mentioned above; that is, open to change through life in common. In other words, the public and social arena of the subjects playing language games together move the background of the form of life without following a prearranged pattern. Starting from this background, let us see how the cultural condition of life form is also creative.

\section{The "pain" of the Philosophical Investigations}

In paragraph 244 of Philosophical Investigations, after having addressed the subject of rule following, Wittgenstein begins a long passage which involves the problem of the relationship between a sensation, which is part of the psychology of the individual, and its redefinition, its "extension" (Z: § 545) or its "refinement" (CE: p. 395), in the public and social space.

At one point Wittgenstein asks himself:

How do words refer to sensations? - There doesn't seem to be any problem here; don't we talk about sensations every day, and name them? But how is the connection between the name and the thing named set up (hergestellt)? This question is the same as: How does a human being learn the meaning of names of sensations? For example, of the

\footnotetext{
4 Von Wright (1982), p. 207.
}

5 See PI 241. 
word "pain". Here is one possibility: words are connected with the primitive, natural, expressions of sensation and used in their place. A child has hurt himself and he cries; then adults talk to him and teach him exclamations and, later, sentences. They teach the child new pain-behaviour.

"So you are saying that the word "pain' really means crying?" - On the contrary: the verbal expression of pain replaces crying, it does not describe it (PI: $\S 244)$.

The English translation quoted translates the verb "herstellen" as "set up"6. In my view, the verb "set up" gives a conventional semantic nuance to the connection between sensation and name, which are preferably avoided for reasons to be explained. "Eine Verbindung herstellen" can also be translated as "create a connection", since "herstellen" has among its meanings "produce, create, make". The following pages try to develop the idea that naming a sensation is a creative act which defines a grammar of behaviour. That behaviour pattern takes place during the production of language games, which is a social fact within a form of life. The sphere of sensations - "whatever it is" (PI: $\S 293)$ - is qualitatively transformed in the public and social space (Da Carolis, 2004, pp. 134-166). Through education and learning, sensation is channelled into the form of life which creates a praxis to express it. This praxis is repeated in language games, whose purpose is to organize existence. Thus, the connection between the level of personal sensations and the social level is a creative process which transforms and redefines the contours of the psychology of the subject during his subjectification. Subjectification is the process which constitutes subjectivities through the relationships which we have together with others in language games.

This connection is far from being an act which constitutes conventions, as perhaps, the English translation suggests, and it seems more like a creative act. The difference is not trivial, since words like "set up" and the like suggest the idea that there is a kind of decision making act that combines two elements with a defined structure: on the one hand, therefore, there would be the sensations with a predetermined shape and, on the other, the names that are associated with them. For instance, on reading a few paragraphs from Remarks on the Philosophy of Psychology, I'm convinced that Wittgenstein imagines the sphere of sensations as undefined and then organized and named within language games. Thus, the original and spontaneous sensation is replaced with a socially defined praxis, and, in any event, recognized as meaningful (RPP: I, $\S \S 305,313)$. Let us read what Wittgenstein writes in paragraph 165 :

6 We find the same translation both in Anscombe's edition and in the recent volume of the Philosophical Investigations edited by Hacker-Schulte (2009). 
"But weren't there all these appearances-of pain, of wishing, of intention, of memory etc., before there was any language?" What is the appearance of pain?- "What is a table?" - "Well, that, for example!" And that is of course an explanation, but what it teaches is the technique of the use of the word "table". And now the question is: What explanation corresponds to it in the case of an 'appearance' of mental life? Well, there is no such thing as an explanation which one can recognize straight away as the homologous explanation (RPP: I, § 165).

What is pain? How can we identify the meaning of the word "pain"? It would not be as simple as identifying the meaning of the word "table", since in this case, through a gesture, we can point to a table and say "this is a table". Even if we pointed at a table to identify the meaning of the word "table", Wittgenstein says, we would not settle its meaning once and for all, but we would define the way in which we use an expression that refers to an object in a particular language game. By pointing at a table to settle the meaning of the word "table", we are only defining the contours of the grammar of use of an expression within a language game (see Gargani, 2008, p. 152). However, let us assume that the meaning of the word "pain" is an object; in this case where would we find this object? And, what kind of object would it be? Maybe a mental picture? Perhaps, an experience of the psyche? Perhaps, a neuronal configuration of the brain? Well, reading Philosophical Investigations and Remarks on the Philosophy of Psychology, we realize that when Wittgenstein talks about the meaning of words and the expressions which refer to phenomena of psychic life - such as meaning, understanding and thinking, he seeks to clarify that the meaning of these words is settled in the circumstances, contexts and practices of life within which we usually use those expressions. In other words, Wittgenstein seems to suggest that even though we busy ourselves looking for a valid psychological object that could be the meaning of the words which refer to a mental phenomenon, in the end, we realize that there is nothing that we can isolate, identify, and, so to speak, hold in our psychological world which provides a good candidate to offer "meaning" to these expressions.

For these reasons, I am lead to believe that the psychological world, conceived by Wittgenstein, is undefined. That world has no form before the intervention of language which creates an organization. In late Wittgenstein, as is well known, language is represented by language games and by the practices which interweave them: the form of life is the human social sphere which organizes and gives a form to the undefined psychological world. Thus, the meaning of psychological expressions is set in the context of language game practices. These practices are: saying these expressions in certain situations, making certain movements, assuming certain stances, carrying out tasks required by the language game, etc. etc. Thus, the undefined subjective psychological sphere is qualitatively transformed when it learns language games. Human social relations act to create semantic behaviour - which 
is organized in language games - which replaces the original and undefined sensation. This discussion leads Wittgenstein to the idea that a psychology which concerns the individual taken in isolation, out of context, turns out to be an abstraction which has nothing to do with the reality of interactions which occur within language games. The subject is immediately inserted into language games; his psychology immediately engages in a relationship with games. His psychology has been transformed within language games through a process of subjectification. As Cavell says, from the time of the Brown Book, Wittgenstein's thought is punctuated by "the idea that language is learned, that one becomes civilized" (Cavell, 1996, p. 32). The subject is then always a "Mitmensch" (see Savigny, 1996), or a "Mitspieler" (see Gebauer, 2005), a peculiarity which cannot be separated from its public and social dimension.

\section{The praxis of joy}

Now, I want to summarize and redefine what I have said in order to better clarify the concepts expressed so far. Wittgenstein refutes the idea that sensation can be an object that resides in a private space in the individual's psyche (PI: $\S \S 261,275$, 293). He denies the idea that within the individual there is a specific object, stored somewhere, which is shown every time we talk about pain, anger, intention or the colour red. Thus, Wittgenstein avoids reducing the level of the semantics of sensation and passions to psychological objects or events, as if, for example, the meaning of joy was a psychological object that is defined in private Cartesian space (see Kenny, 2006, pp. 13, 141-159; Budd, 1961, p. 66). However, in my opinion, Wittgenstein goes further. He says that whatever happens in the psyche of the individual, this is then redefined and transformed in the social space (PI: § 293). The meaning of "joy", for example, is therefore a mosaic of semantic praxis: saying something in certain contexts, facial expressions, gestures and body posture, actions towards others who share their joy. That behaviour is performed in the sphere of language games and involves people who live an established form of life.

"I feel great joy"-Where?-that sounds like nonsense. And yet one does say "I feel a joyful agitation in my breast".-But why is joy not localized? Is it because it is distributed over the whole body? Even where the feeling that arouses joy is localized, joy is not: if for example we rejoice in the smell of a flower--Joy is manifested in facial expression, in behaviour. (But we do not say that we are joyful in our faces) (Z: § 486).

"But I do have a real feeling of joy!" Yes, when you are glad you really are glad. And of course joy is not joyful behaviour, nor yet a feeling round the corners of the mouth and the eyes. 
"But 'joy' surely designates an inward thing." No. "Joy" designates nothing at all. Neither any inward nor any outward thing $(Z: \S 487)$.

The behaviour of joy, the praxis of joy, have been learned and experienced through actions which involve players of the language game. How do I teach someone the meaning of the word "pain"? Wittgenstein asks. Certainly not by pushing him to view his inner and private psyche; but "Perhaps by means of gestures, or by pricking him with a pin and saying, "See, that's pain!"” (PI: $§ 288)$. And the person who is learning the meaning of the word "pain" will show his understanding not by showing the sample of pain that resides in his private psyche, but "he will show it by his use of the word, in this as in other cases"(PI: $\S 288)$.

This process of redefinition and transformation is, from my point of view, a creative process that a form of life goes through when it has to organize existence. The original instinctual world of the individual is imagined by Wittgenstein as something corporeal, which assails the actions of the body: "In the beginning was the deed. (...) The basic form of the game must be one in which we act" (CE: pp. 395397). And this original instinctual world is, as I believe, something disordered, undefined, which receives shape in the form of life. Through the creation of behaviour that is considered meaningful, the form of life gives order to that original semantic world of spontaneous bodily reactions:

The origin and primitive form of the language game is a reaction; only from this can more complicated forms develop.

Language -I want to say- is a refinement (CE: p. 395).

Let us consider, for example, how pain is socialized after a death in certain farming and fishing communities in Italy in the last century. There is in fact an elaborate and meticulous organization of behaviour, considered socially meaningful and necessary, which must be adopted in the presence of pain in bereavement. It is an organization which deeply affects the life of the whole community and modifies habits, places and routine to ensure that the pain can be properly expressed. This organization penetrates every aspect of the community's life. Every member of the community must behave according to the rules which mourning requires.

It is not about to bring back any form of relativism or incommensurability. I am focussing on the relation between individual's psychology and social context. How is an individual's psychology put in common with social rules? How does an individual's psychology engage in the social structure of rules, habits, customs and behaviour? These are the issues I am working on via Wittgenstein later philosophy. 


\section{The beetle in the box and the unknowability of psychic life}

Paragraph 293 of Philosophical Investigations is quite illuminating regarding the connection between psychic life and language games:

Well, everyone tells me that he knows what pain is only from his own case! - Suppose that everyone had a box with something in it which we call a "beetle". No one can ever look into anyone else's box, and everyone says he knows what a beetle is only by looking at his beetle. - Here it would be quite possible for everyone to have something different in his box. One might even imagine such a thing constantly changing. - But what if these people's word "beetle" had a use nonetheless? - If so, it would not be as the name of a thing. The thing in the box doesn't belong to the language-game at all; not even as a Something: for the box might even be empty. - No, one can 'divide through' by the thing in the box; it cancels out, whatever it is (es hebt sich weg, was immer es ist).

That is to say, if we construe the grammar of the expression of sensation on the model of 'object and name', the object drops out of consideration as irrelevant (PI: § 293).

As mentioned, psychological processes which are expressed directly through actions are redefined in social contexts (PI: $\S 296)$, within which a grammar of behaviour, which is part of language games, replaces spontaneous and instinctive reactions. Therefore, these psychological processes or instinctive actions expressed through the body during training in games take on a meaningful form which depends on the language game played within a form of life. This theoretical approach tends towards the idea that the production of cultural forms of life creates, through certain choices, a series of meaningful, socially accepted behaviour which organizes the original instinctual world.

But, reading that paragraph in Philosophical Investigations, one can reach even more radical conclusions. Let us see why. If the sphere of sensations is transformed within the social space of language games through a linguistic behaviour pattern which replaces and redefines the original sensation, whatever that sphere is, it is lost in the language - it is cancelled out (es sich hebt weg), Wittgenstein says (PI: § 293) - because it is qualitatively transformed through participation in the games. The learning of characteristic behaviour for fear or joy changes immediate and spontaneous reactions. This characteristic behaviour is learned by participating in language games. And since we are linguistic animals, embedded in language, and from which we cannot come out ${ }^{7}$, if we decided to track down the original sensation the beetle in our box - we would not be able to because it was transformed during

\footnotetext{
7 Wittgenstein seems to go in that direction when he says for instance: "Can only those hope who can talk? Only those who have mastered the use of a language. That is to say, the manifestations of hope are modifications of this complicated form of life." (PI: II, i, 1).
} 
the learning of language. This means that if this line of reasoning is followed, we come to the radical conclusion that our psychic life is unknowable, because the learning of language games transforms that psychological world, it does not identify it 8 :

A cry is not a description. But there are transitions (Übergänge). And the words "I am afraid" may approximate more, or less, to being a cry. They may come quite close to this and also be far removed from it ( $L W: \S 51)$.

The cry, which is an instinctive and therefore spontaneous reaction, does not describe anything, does not identify any object of our inner world. Moreover, by participating in games, the instinctive reaction has "Übergänge" in the language in various ways, depending on the language game of the life form. Since we are not allowed to leave the sphere of language games, we do not possess elements to identify and to know that psychological world which, for example, helps to generate the cry. For this reason I claim that the sphere of sensations - that original and spontaneous substratum which arises beyond language - is undefined. In other words, in Wittgenstein's philosophy of psychology it is impossible to observe and identify both the original sensation (see $L W: \S 407$ ) and anything else that is part of the psychic life of the individual. By having given a name to a sensation, by having taken part in language games, we have included that sensation in one or more games which have produced transformations in the individual during his process of subjectification. Moreover, if we want to analyse language in order to identify any psychological object, we would actually only describe the grammar of language game concepts (see, for example, $L W$ : from $\S 13$ to $\S 51$ ) because what is outside the language games is undefined (RPP: I, $\S 165)$.

We would therefore only analyse the grammar of the language games through an analysis of the concepts of language. It is an analysis of the expressions used in games, and not an analysis of referential reality which arises out of them. If I point to a table to identify the meaning of the word "table", I do not achieve my objective because by doing so I have just given an example of how to use the phrase "this is a table" in a specific language game: I am therefore dealing with the description of a grammar game. In other words, the objects used in games are not objects that identify reality, but are constructed objects, created, manipulated and transformed into forms of life by social and human power, which is a creative power. In my view, that is the profound criticism which Wittgenstein launches at the referential semantic model of language "Word $\rightarrow$ Object". That model does not identify reality through a referential process. By giving a meaning to something, we change this

8 This point of view is very close to a Kantian view, since according to Kant, we cannot know "das Ding an Sich", but only our tools of representation of the world. 
thing through creative acts and processes. Whatever it is, something is brought into the life form. A meaningful form is thus given to that reality which stands outside of language games. This, in my opinion, is the constructivist view to which I would ascribe Wittgenstein's later philosophy.

If we follow this line of thinking, we are inclined to believe that reality takes a form via acts of invention: creative acts. Since reality-in this case psychological reality-has no objects with a predetermined shape, acts of creativity, embodied in a linguistic praxis within language-games, construct an order made of patterns of praxis ritualized in language-games. In this sense, form of life does not give a possible order to existence through conventions we do not attribute meaning to things via decision making, but via inventions, practising our creativity. Those inventions becomes behaviour patterns within language games. Therefore, we do not stipulate conventions through decisions which attribute a name to a thing, but we create (herstellen) a linguistic praxis within a language game. As already said, this praxis, from my point of view, is a creative process, and not a decision making process: reality is produced (hergestellt, PI § 244) by the praxis. It is neither reflected by language nor organized by conventional decisions which attribute a name to pre-shaped things.

\section{The path to change}

Does the process of subjectification, described in the previous paragraphs, lead to a form of social determinism? Is the process of subjectification determined by language games? Does it mean that the sphere of Self is shaped and manipulated by the rules of socially shared games? Could the sensations, passions and whole psychology of the subject be determined by education and training in language games? Forms of life organize existence in different ways through linguistic games and in a way to create meaningful behaviour. In the case of the sensations and psychological sphere of the subject tout court, this behaviour replaces and transforms original instinctive reactions. This process is developed through the practice of language games. However, is there then perhaps a total manipulation of the games in the formation of subjectivity?

In this section I would like to propose the idea that the undefined nature of the psychological sphere, which was discussed formerly, is recognized by the fact that no matter how someone can express pain, joy or anger according to the social rules which have transformed the original reaction, there is always something that escapes social organization and goes beyond the rules. What escapes and remains undefined is the engine of change in the language game. In other words, the indefinite nature of the body which has spontaneous reactions to the different contexts of 
life is never completely organized within the game, something always escapes the rules. This something can trigger change, trigger reorganization which is also a creative process. There is, of course, the characteristic behaviour of joy encoded in language games, semantic regularities that are usually observable when we have to give meaning to joy. However, this behaviour, defined and fixed by rules learned through participation in the games, can change through the creative work of individuals in the process of subjectification. That means that the subjects get involved in a dynamic relationship with what they learn in language games. This dynamic relationship is expressed in an oscillation between degrees of acceptance and rejection of the characteristic behaviour encoded in games (on this issue see De Carolis (2008)). So, Wittgenstein outlines the idea that there is an oscillatory movement which, on the one hand, acquires game techniques and transforms the Self of the subject through participation in the games. On the other, it rejects these techniques and opens the way to diversification and change. The rejection of the rule is for instance represented by the pupil who is unable to follow the rule as we would have expected, as socially recognized as "normal". On that occasion, in his discourse on rule-following (see $P I$ : $\S \S 185-241$ ), Wittgenstein remarks that the creativity of speakers can come out within the indeterminate space which opens between the normativity of the rule and its application in a new case. No rule predetermines its new application (see Kripke, 1982; Budd, 1984; McDowell, 1984). The rule can point to a known track, but whether it is the case to follow this track is a decision that the individual has to take (PI: $\S 186)$. So, the subject can choose to show behaviour which repeats an orthodox application of the rule. He can distance himself partially from the orthodox rule by exhibiting deviant behaviour. He can completely reject the behaviour that is considered normal and can therefore act in a highly creative way. This gap created between the rule and its new application is a no man's land (see Virno, 2005, pp. 37-42), in which experimentation and creativity can better operate.

\section{The "rage" of Wittgenstein and Sraffa}

The main idea, from which the consequences for creativity then spring, refers to the radical unpredictability of the application of the rule in a new case. This was an idea with which Wittgenstein really struggled. In fact, in the thirties when he returned to Cambridge, Wittgenstein develops ideas on the radical mutability of life form. Signs of the laborious progress on this idea can be traced in 1934 through a curt exchange of opinions between Wittgenstein and Sraffa (see LD: pp. 222-229). They debate the dynamics of change in meaning. How does it happen? Why is it? And how does it occur? Things become very heated between them, so much so that 
Wittgenstein threatens to stop talking to the Italian economist (LD: p. 224). The arguments into which they stumble are the possible Nazification of Austria, the physiognomy of rage and the relationship between past and future events. Wittgenstein criticizes the idea that events to which we have given a name can necessarily be repeated in the same way. In particular, Wittgenstein criticizes Sraffa's idea according to which it would be easy to imagine the Nazification of Austria observing what had happened in Germany and Italy. Similarly, he criticizes the idea that imagining someone in a state of rage means imagining him with certain contracted facial muscles contract, as "normally" happens. Thus, Wittgenstein criticizes the idea that the future meaning of the word "Nazification" can be predicted in advance, for example by observing the behaviour that constitutes the processes which occurred in the past. Wittgenstein expresses concern about the fact that the characteristic behaviour of rage, which constitutes the current meaning of the word "rage", can constitute the basis for understanding how rage will be expressed in the future. Thus, Wittgenstein criticizes the idea that the future physiognomy of rage can, for example, be imagined and predicted if you ask a physiologist how the muscles of the face contract. Wittgenstein argues that the response of the physiologist is not the only one possible. Indeed, a painter might re-imagine the characteristics of rage differently.

Wittgenstein seems to be very interested in untying any causal and deterministic relationship between the present and past meaning and its new application. As said earlier, that is a theme that can be found in Philosophical Investigations, in the reflections on intention and rule following. In other words, even if we collected all occurrences of past and present events to which we have given meaning through a name, we would not have any element of knowledge to predict what will happen in the future. It could still be the case that the unexpected appears and we are forced to reinvent some conceptual categories in a creative way:

You say: "Learn from what has happened in Italy". But what should I learn from them? I don't know exactly how things happened in Italy. So the only lesson I could draw from it is, that things one doesn't expect sometimes happen (LD: p. 223).

In a note that Wittgenstein wrote in February 1934 (LD: pp. 225-226), he decides to organize and further clarify his thoughts on the topic which had led to the misunderstandings with Sraffa. In that note, Wittgenstein criticizes the idea that the evolution of reality can be closed within one or more meanings which are held in the mind. He criticizes the metaphysical claim that reality is determined by a state of mind and, in particular, that there is a cause-effect relationship between the patterns of thought and reality. 
Now the fallacy which I want to point out is this, - to think every action which people do is preceded by a particular state of mind of which the action is the outcome ( $L D: \mathrm{p}$. 225).

Thus, Wittgenstein is criticizing the idea that closed and static forms of thought can determine the course of reality. He criticizes the idea that actions are somehow caused by conceptual schemes. Wittgenstein seems to refute the fact that this metaphysical approach delimits reality within confines in a way that is difficult to open to change and innovation. Earlier, we saw that Wittgenstein expresses the idea that the past occurrence of an event does not determine anything in a new case. And now in the same way he criticizes the idea that no rule, stored in any part of the mind, can predict in advance the development of events. In fact, if we followed a metaphysical approach to the question "Is a King possible without a crown?" ( $L D: \mathrm{p}$. 225), we would possibly answer:

No, because it doesn't fit the character of a King not to have a crown, or it doesn't fit into the physiognomy of Royalty if the King hasn't a crown ( $L D:$ p. 225).

However, Wittgenstein says the correct answer is:

Well that physiognomy will just change and there will be Kings without crowns ( $L D$ : p. 225).

Reality is much richer and more unpredictable than its conceptual form: that seems to be Wittgenstein's opinion. Moreover, past events that have developed in a certain way and have established a pattern of meaningful behaviour - a physiognomy that we have named- are not decisive in a new occurrence of such events. The fact that in Germany and in Italy Nazism and Fascism assumed certain characteristics, a certain physiognomy (a behaviour pattern), does not determine anything about the processes which were taking place in Austria. Wittgenstein refutes the metaphysical pretension that thought and meaning could circumscribe the world and crystallize it in a static form which rejects any change. But, actually, there is no constraining and deterministic connection between past events and future. As Wittgenstein points out, reality is more complex, because it can introduce innovation that is inconceivable observing only the shape of meaning that has defined the world in a certain way. What is unexpected for the conceptual framework is always theoretically and practically possible.

So Wittgenstein continues his discourse, using a very interesting example, he says: 
If I had observed a body moving in a circle and it had just completed its first round like this

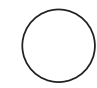

then I might be so strongly impressed by this picture that it would seem to me impossible that the body when it continues its movement should move in anything but the same circular path again. For, I should argue, its motion has the physiognomy of a circle. But suppose it continued this way

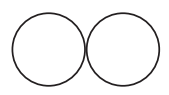

then of course this hasn't the old physiognomy but a very simple new one and as soon as I see it I will again be tempted to think that now the body must obviously move on in the shape of an eight.

It will therefore be correct to say, as you did: "If you want to know what will happen with Germany, don't argue from its physiognomy and things like this." But not because this physiognomy is too vague. Not at all. But because in arguing from the physiognomy one argues from a prejudice that certain things will not change, although there is no reason to suppose they won't.

We store away impressions in our mind, certain standards (such as that of the King with a crown) and are inclined to think that everything we may meet must conform with these standards. But if we met with a Kingdom in which the King has no crown we would soon enough put this in our collection of standards too ( $L D:$ p. 226).

Reading this text it is clear that Wittgenstein criticizes any metaphysical idea which attempts to restrict reality in a semantic form. Physiognomy has a stable structure. The pattern of physiognomy consists in semantic regularities and behaviour to which we refer when we speak and perform within language games. Sometimes, Wittgenstein says, we believe that reality must conform to these semantic regularities that are stored in our minds. However, if we arrived in a kingdom where there are uncrowned kings, we could easily redefine our semantic paradigms.

\section{Meaning and Body}

The psychology of the individual is modified within language games. It is not transformed in a deterministic way, but it establishes a complex relationship between what is learned and what we want to change. The individual learns socially defined behaviour which changes the instinctive reactions which we experience within language games. This learning process can, however, lead to changes in the game which might not be predictable. In this context, the role that the body has in the definition of semantics is very interesting. Socially shared meanings become 
manifest and visible through certain stances that the body assumes, through various gestures and movements that the body makes: through certain phrases expressed in certain circumstances:

I am interested to know what phrases the Austrians will use when they'll have turned Nazi. Supposing their patriotism is only talk then I'm just interested in their future talk (LD: p. 223).

Thus, the meaning of the word "rage" is manifest through the physiognomy of the body, the look on one's face, through the gestures and movements which the body makes. The meaning becomes manifest through the words that are said in the context of a game within which we express anger. The meaning becomes manifest in the dynamics of the game which produces anger among the players. And how we express anger in the future, in a new context, is radically unpredictable according to Wittgenstein. The individual that acts is a body which acts. It is a socialized body which moves in the social sphere of the language game. Movements of this body, facial expressions, gestures, pronounced sentences are the physiognomy of meaning. (On the relationship between body and meaning in Wittgenstein's late philosophy see Fabbrichesi Leo, 2000; Fortuna, 2002; Virno, 2003, pp. 91-110). Moreover, Wittgenstein also seems interested in understanding why this symbolic embodied order changes (On the relation between embodiment and Wittgenstein's Philosophy see Hutto, 2013; and Moyal-Sharrock, 2013). He traces the force behind the mutability of life form in the radical unpredictability of rule application.

It seems that Wittgenstein is concerned with the elements of production and reproduction of semantics. That process constitutes a form of life, a regulated form of existence that is open to change. That production and reproduction happen within language-games, within which bodies move according to the rules. These rules can be recognized from the aesthetics ${ }^{9}$ of the movements of these bodies (On aesthetics and body in Wittgensteins's philosophy see Cometti, 2010). The body movements are gestures it produces, actions it performs, the physiognomies and the forms it takes. Once all metaphysics are rejected, the body becomes the privileged place of semantics. Meaning is embodied, in the sense that it is directly visible through the movements of the body. Once we discard the idea that meaning can be found within the body in a private Cartesian space or in a secret space of psychology, or beyond it in a metaphysical realm, the body itself becomes the theatre of meaning. The body moves within language games. Its movements are meaningful because it has been trained to move in that way. The body receives an education in the games to be able to move more easily and in agreement with others. Meanings

\footnotetext{
${ }^{9}$ Aesthetics is intended as knowledge that is possible through the senses and not necessarily only through conceptual aspects.
} 
become visible through the body; they themselves become body through its movements. Thus, Body moves within games and creates semantic relationships with others. The contexts of the game allow players to show their ability to move and make the correct moves. The contexts of the game involve the player whose psychology is immediately made public in social situations. The subject is immediately social. The sphere of subjectivity is continuous alongside sociality (see Cimatti, 2007). It is a sphere that is always present and the subject must constantly communicate with it. In language games, the body shows its ability to play with others. Every movement is meaningful. Gestures of the body are also phrases that it pronounces in situations with others (see PI: § 435; Z: §§ 158-159; Gargani, 2008; Gebauer, 2009, pp. 75-105). The indefinite of the body is not, however, ever fully conveyed within the rules of society. Something escapes and can push towards the negation of these rules and might therefore start processes which go in the direction of creativity, the differentiation and transformation of the life form.

\section{Conclusions}

To draw some conclusions from concise formulae, it can be said that the body which performs in the context of language games - the body which has a psychic life shared through relationships established in the games- is plastic because it is redefined within them. Giving a name to sensations and then to passions, it reorganizes psychic life which enters in contact with language games. The language games are public and social contexts within which something is done and in which we express our sensations and passions. We also learn to express feelings and passions by the rules. Nevertheless, while the body is plastic, it is not necessarily docile; indeed, it may be recalcitrant, because, by refusing to follow an already defined semantic track, the body can start changing processes within language games, since it can use the undefined space which the radical unpredictability of rule application leaves open. By crossing this no man's land that the gap between rule and application opens, it provides the opportunity to start a process of experimentation, which might lead to change the life form.

If we agree with these ideas, then it is possible to interpret the Wittgensteinian concept of life form in the same terms as Agamben in his essay "Form-of-Life" (Agamben, 1993). As seen, if life forms organize and reorganize creatively through the invention of language games, an existence which in itself is undefined, then the life form might be described as a possibility of existence, a possibility of life (Agamben, 1993, p. 107). It is an ongoing process and not something that is crystallized in a biological or cultural form. In other words, life is not structured in one or more static forms, it takes on a possible form, which is never final and always 
open to change in its becoming, making itself concrete and historical. Life takes a form that is not a priori, but is built on its development through non-deterministic processes. On the one hand, life takes on a certain form in its development, thus taking on a form, but at the same time an escape from this temporary form opens up. While it follows a path of historicization, the life form always has a forked path which can potentially lead it elsewhere and in an unpredictable direction.

\section{Bibliography}

Abbreviations of Wittgenstein's works:

CE: "Ursache und Wirkung: Intuitives Erfassen / Cause and Effect: Intuitive Awareness", in Ludwig Wittgenstein, Philosophical Occasions 1912-1951, pp. 370-426, James C. Klagge and Alfred Nordmann eds, Indianapolis and Cambridge, USA, Hackett, 1993.

LD: Wittgenstein in Cambridge. Letters and Documents 1911-1951, edited by Brian McGuinness, Maden USA - Oxford UK - Victoria Australia, Blackwell Publishing, 2008.

LW: Last Writings on the Philosophy of Psychology / Letzte Schriften über die Philosophie der Psychologie, G.H. and Wright und Heikki Nyman eds, translated by C.G. Luckhardt and Maximilian A.E. Aue, Oxford, Basil Blackwell, 1982.

PI: Philosophical Investigations, G.E.M. Anscombe and R. Rhees eds, translated by G.E.M. Anscombe, Third edition, Oxford, Basil Blackwell, 1968. Reference also to Philosophical Investigations. The German text, with an English translations by G.E.M. Anscombe, P.M.S. Hacker and Joachim Schulte. Revised 4h edition by P.M.S. Hacker and Joachim Schulte. Malden, Oxford, Chichester, Wiley-Blackwell, 2009.

RPP: Remarks on the Philosophy of Psychology / Bemerkungen über die Philosophie der Psychologie, G.E.M. Anscombe and G.H. vonWright eds, translated by G.E.M. Anscombe, Oxford, Basil Blackwell, 1980.

Z: Zettel, G.E.M. Anscombe and G.H. vonWright eds, translated by G.E.M. Anscombe, second edition, Oxford, Basil Blackwell, 1981. 


\section{Other Bibliography}

Agamben, G. (1993): "Forma-di-vita" in AA.VV., Politica, Cronopio, Napoli, pp. 107-112; then in AA.VV., Comunità e politica, Cronopio, Napoli, pp. 89-94.

BudD, M. (1984): “Wittgenstein on Meaning, Interpretation and Rules", In Synthese 58, pp. 303-323.

Budd, M. (1961): Wittgenstein's Philosophy of Psychology, London-New York, Routledge.

Cavell, S. (1996): "The Normal and the Natural", in The Cavell Reader (edited by Stephen Mulhall), Blackwell Publishers Ltd, Oxford, 1996, pp. 31-45.

Cimatti, F. (2007): Il volto e la parola. Psicologia dell'apparenza, Macerata, Quodlibet.

Cometti, J. P. (2010), "Aesthetic Experience and Foms of Life", in Marques A. Venturinha N. (eds), Wittgenstein on Forms of Life and The Nature Of Experience, Peter Lang, 2010, pp. 65-74.

De CARolis, M. (2008): Il paradosso antropologico. Nicchie, micromondi e dissociazione psichica, Macerata, Quodlibet.

De CARolis, M. (2004): La vita nell'epoca della sua riproducibilità tecnica, Torino, Bollati Boringhieri.

FABBRICHESI LEO, R. (2000): I corpi del significato. Lingua, scrittura e conoscenza in Leibniz e Wittgenstein, Milano, Jaca Book.

Fortuna, S. (2002): A un secondo sguardo. Il mobile confine tra percezione e linguaggio, Roma, Manifestolibri.

Gargani, A. G. (2008): Wittgenstein. Musica, parola, gesto, Milano, Raffaello Cortina.

Gebauer, G. (2009): Wittgensteins anthropologisches Denken, München, Verlag C. H. Beck.

Gebauer, G. (2005): "Praktischer Sinn und Sprache", in (2005) [Herausgegeben von Catherine Colliot-Thélène, Etienne François und Gunter Gebauer] Pierre Bourdieu: Deutsch-französische Perspektiven, Frankfurt am Main, Suhrkamp Verlag, pp. 137-164.

HACKER, P.M.S. (2011): "Language, Language-Games and Forms of Life", in Padilla Gálvez J., Gaffal M. (eds), Forms of Life and Language Games, Ontos Verlag, Frankfurt-Paris-Lancaster-New Brunswick, pp. 17-37.

HACKER, P.M.S. (2010): "Wittgenstein's Anthropological and Ethnological Approach", in Padilla Gálvez (ed.), Philosophical Anthropology. Wittgenstein's Perspective, Ontos Verlag, Frankfurt-Paris-Lancaster-New Brunswick, pp. 1533.

HutTo, D. (2013): "Enactivism, From A Wittgensteinian Point of View", in American Philosophical Quarterly, 7, 2013. 
Kenny, A. (2006): [Revised Edition] Wittgenstein, Malden, Oxford and Carlton, Blackwell Publishing.

KRIPKE, S. (1982): Wittgenstein on Rules and Private Language. An Elementary Exposition, Cambridge Massachusetts, Harvard University Press.

McDowell, J. (1984): "Wittgenstein on Following a Rule", in Synthese 58, pp. 325-363.

Moyal-Sharrock, D. (2013): "Wittgenstein's Razor: The Cutting Edge of Enactivism", in American Philosophical Quarterly, 7, 2013.

SAVIGNY, E. von (1996): Der Mensch als Mitmensch. Wittgensteins "Philosophische Untersuchungen", München, Dt. Taschenbuch-Verlag.

VIRno, P. (2005): Motto di spirito e azione innovativa. Per una logica del cambiamento, Torino, Bollati Boringhieri.

VIRNO, P. (2003): Quando il verbo si fa carne. Linguaggio e natura umana, Torino, Bollati Boringhieri.

Wright vON, G. H. (1982): "Wittgenstein in relation to his Times" in G.H. von Wright, Wittgenstein, Basil Blackwell, Oxford, 1982, pp. 201-216.

Emiliano La Licata

University of Palermo

emiliano.lalicata@gmail.com 